\title{
A Compact Dual-Band Octagonal Slotted Printed Monopole Antenna for WLAN/ WiMAX and UWB Applications
}

Praveen V. Naidu ${ }^{1}$ and Raj Kumar ${ }^{2}$

${ }^{1}$ Centre for Radio Science Studies, Symbiosis International University (DU), Pune, India

${ }^{2}$ ARDE, Pashan, Pune - 411 025, India

Email: raj34_shivani@yahoo.co.in

\begin{abstract}
A compact $\left(20 \times 20 \mathrm{~mm}^{2}\right.$ size), coplanar waveguide (CPW) fed, octagonal slotted, dual-band antenna is presented in this paper. The proposed antenna has a simple structure consisting of an octagonal slot, L-shape stub, and a two stepped rectangular patch. The introduction of the L-shaped metallic stubs in the ground plane generates a lower resonance frequency at $2.42 \mathrm{GHz}$. The proposed antenna is fabricated on a low cost FR4 substrate having thickness of $1.6 \mathrm{~mm}$. The measured impedance bandwidth of the proposed antenna is from 2.40 to $2.46 \mathrm{GHz}$ and 3.2 to 6.2 GHz. It is also shown that the proposed antenna has stable radiation patterns of almost dumb-bell shape in the E-plane and omni-directional shape in the H-plane. The effects of various design parameters on the impedance bandwidth are also studied and presented in detail. The proposed antenna can be used for $3.5 / 5.5$ GHz worldwide interoperability for microwave access (WiMAX), 2.4/5.2/5.8 GHz wireless local area network (WLAN) and 3.1-6.0 GHz Direct-Sequence Code Division Multiple Access (DS-CDMA) / Multi-Band Orthogonal Frequency Division Multiplexing (MBOFDM) ultra wideband (UWB) applications.
\end{abstract}

Index Terms - CPW-fed, DS-CDMA, MB-OFDM, dual-band, slot antenna, WLAN, WiMAX and UWB antenna.

\section{INTRODUCTION}

In recent years, much attention has been paid towards the development of multi-band antennas with low cost, compact size and ease of fabrication. These antennas are required to have higher performance and intended for wireless communication applications such as wireless local area network (WLAN), worldwide interoperability for microwave access (WiMAX) and MB-OFDM / DSCDMA UWB systems. Many printed dual-band and UWB monopole antennas were reported for various wireless applications in the literature [1-13]. Among them, CPW-fed slot antennas have many advantages like simple structure, ease of fabrication, wide impedance bandwidth, less radiation loss and ease of integration with monolithic microwave integrated circuits (MMIC).

A $60 \times 45 \mathrm{~mm}^{2}$ and $40 \times 40 \mathrm{~mm}^{2}$ size dual-band slot antennas for $2.4 / 5 \mathrm{GHz}$ WLAN applications are proposed in [1-2] respectively. In [3], a $32 \times 16 \mathrm{~mm}^{2}$ size ring monopole antenna with two meander lines was reported for $2.4 / 5 \mathrm{GHz}$ dual-band operations. Similarly several dual-band slot 
antennas like a rectangular shaped slot antenna [4], a cross shaped slot antenna [5] and a triangular slot antenna [6] were proposed for wholly cover $2.4 / 5 \mathrm{GHz}$ WLAN bands. Though the reported antennas cover all $2.4 / 5 \mathrm{GHz}$ WLAN bands, but they are not very compact in size as well as they are not able to cover $3.5 \mathrm{GHz}$ WiMAX band. In [7], a dual-band monopole antenna is designed by protruding stubs in the ground plane. The presented antenna has an overall size of $35 \times 50 \mathrm{~mm}^{2}$ and it is covering only $2.4 \mathrm{GHz}$ and $5.8 \mathrm{GHz}$ WLAN bands. In [8], a dual-band slot antenna comprising of two narrow linear slots for WLAN applications was presented, and in [9], a $50 \times 75 \mathrm{~mm}^{2}$ double Tshaped monopole dual-band antenna was proposed for WLAN applications but both the presented antennas have a drawback of covering only $2.4 \mathrm{GHz}$ and $5.2 \mathrm{GHz}$ WLAN bands. The dual frequency operation was achieved by using CPW-fed antenna with inverted L strip and open ended rectangular ring strip in [10], the overall dimensions of the proposed antenna was $26.5 \times 25 \mathrm{~mm}^{2}$ which covers only $2.4 \mathrm{GHz}$ and $5 \mathrm{GHz}$ WLAN bands.

In [11], a 35 x $24 \mathrm{~mm}^{2}$ size triangular shaped coplanar waveguide fed monopole antenna was proposed for 2.4/5 GHz WLAN and 3.4 GHz WiMAX applications. But again the overall dimensions of the antenna are larger when compared with our proposed design $\left(20 \times 20 \mathrm{~mm}^{2}\right)$. Also many researchers have reported UWB antennas [12-13] for MB-OFDM) / lower band DS-CDMA systems with a frequency range of $3.1 \mathrm{GHz}$ to $4.8 \mathrm{GHz} / 3.1 \mathrm{GHz}$ to $5.15 \mathrm{GHz}$. In [13], a compact $20 \times 30$ $\mathrm{mm}^{2}$ tree shaped fractal UWB antenna is presented for MB-OFDM lower three band (3.1-4.8 GHz) applications. Some of the reported antennas perform well in the bandwidth and radiation characteristics, but because of large relative size, they may be difficult to be integrated with miniaturized communication devices. So there is a demand for designing compact multi-band antennas having wideband characteristics. Table 1 shows the comparison of antenna size, operating bands and antenna purpose of the proposed antenna with antennas reported in [1-11].

In this paper, we have proposed a compact dual-band CPW-fed octagonal slot with rectangular shaped patch antenna covering the operating bands of 2.4/5.2/5.8 GHz WLAN bands, 3.5/5.5 GHz WiMAX band and 3.1-6.0 GHz DS-CDMA/MB-OFDM UWB band. The proposed antenna is compact in size $\left(20 \times 20 \mathrm{~mm}^{2}\right)$, and designed, optimized and simulated using 3D-electromagnetic software CST Microwave Studio based on the Finite Integration Technique (FIT). The reflection coefficient characteristic of the fabricated antenna is measured using Rohde \& Schwarz Vector Network Analyzer (R\&S ZVA-40) while the radiation patterns and gain are measured in an in-house anechoic chamber. Finally, the simulated and measured results are compared and discussed.

Table 1- Comparison of proposed antenna performance with other compact antennas 


\begin{tabular}{|c|c|c|c|c|c|}
\hline S.No & $\begin{array}{c}\text { Published } \\
\text { literature/ } \\
\text { proposed }\end{array}$ & $\begin{array}{c}\text { Antenna } \\
\text { Size (mm2) }\end{array}$ & $\begin{array}{c}\text { Total area } \\
\text { occupied by the } \\
\text { antenna (mm2) }\end{array}$ & $\begin{array}{c}\text { Frequency bands } \\
\text { covered }\end{array}$ & Antenna purpose \\
\hline 1 & Ref [1] & $60 \times 45$ & 2700 & $2.4 / 5.2 / 5.8 \mathrm{GHz}$ & Tri-band \\
\hline 2 & Ref [2] & $40 \times 40$ & 1600 & $2.4 / 5.2 / 5.8 \mathrm{GHz}$ & Dual-band \\
\hline 3 & Ref [3] & $32 \times 16$ & 512 & $2.4 / 5.2 / 5.8 \mathrm{GHz}$ & Dual-band \\
\hline 4 & Ref [4] & $75 \times 75$ & 5625 & $2.4 / 5.2 / 5.8 \mathrm{GHz}$ & Dual-band \\
\hline 5 & Ref [5] & $43 \times 41$ & 1763 & $2.4 / 5.2 / 5.8 \mathrm{GHz}$ & Dual-band \\
\hline 6 & Ref [6] & $75 \times 75$ & 5625 & $2.4 / 5.2 / 5.8 \mathrm{GHz}$ & Dual-band \\
\hline 7 & Ref [7] & $50 \times 35$ & 1750 & $2.4 / 5.8 \mathrm{GHz}$ & Dual-band \\
\hline 8 & Ref [8] & $200 \times 260$ & 52000 & $2.4 / 5.2 \mathrm{GHz}$ & Dual-band \\
\hline 9 & Ref [9] & $50 \times 75$ & 3750 & $2.4 / 5.2 \mathrm{GHz}$ & Dual-band \\
\hline 10 & Ref [10] & $26.5 \times 25$ & 702.25 & $2.4 / 5.2 / 5.8 \mathrm{GHz}$ & Dual-band \\
\hline 11 & Ref [11] & $35 \times 24$ & 840 & $2.4 / 3.4 / 5.2 / 5.8 \mathrm{GHz}$ & Dual-band \\
\hline 12 & Proposed & $20 \times 20$ & 400 & $2.4 / 3.5 / 5.2 / 5.5 / 5.8$ & Dual-band \\
& work & & & $\mathrm{GHz}$ & \\
\hline
\end{tabular}

\section{ANTENNA GEOMETRY}

Fig. 1 shows the geometry of the proposed octagonal slotted rectangular shaped patch antenna for dual-band operation. The proposed antenna has overall dimensions of $20 \times 20 \mathrm{~mm}^{2}$ and is designed on an inexpensive FR4 substrate of thickness $1.6 \mathrm{~mm}$, relative permittivity 4.3 and loss tangent $\tan \delta=0.019$. The octagonal slot is etched on the ground plane and contains the radiating element which is a two stepped rectangular patch. A $50 \Omega \mathrm{CPW}$-fed transmission line, which consists of a strip of width $3 \mathrm{~mm}$ and a gap distance of $0.5 \mathrm{~mm}$ between the strip and the ground plane, is used to excite the antenna. Both the ground plane and the patch are printed on the same side of the substrate. As further seen from the figure, three metallic stubs are attached to the ground plane above and below the patch. The major effect of the inserted L-shaped stub in the ground plane is to produce another current path at $2.4 \mathrm{GHz}$ band, and thus exciting a new resonant frequency. The rectangular patch of height 'b16' (Fig. 1) gives the higher cut-off frequency near $5.88 \mathrm{GHz}$ while the patch width 'g8' is optimized to get the best return loss characterstic. 


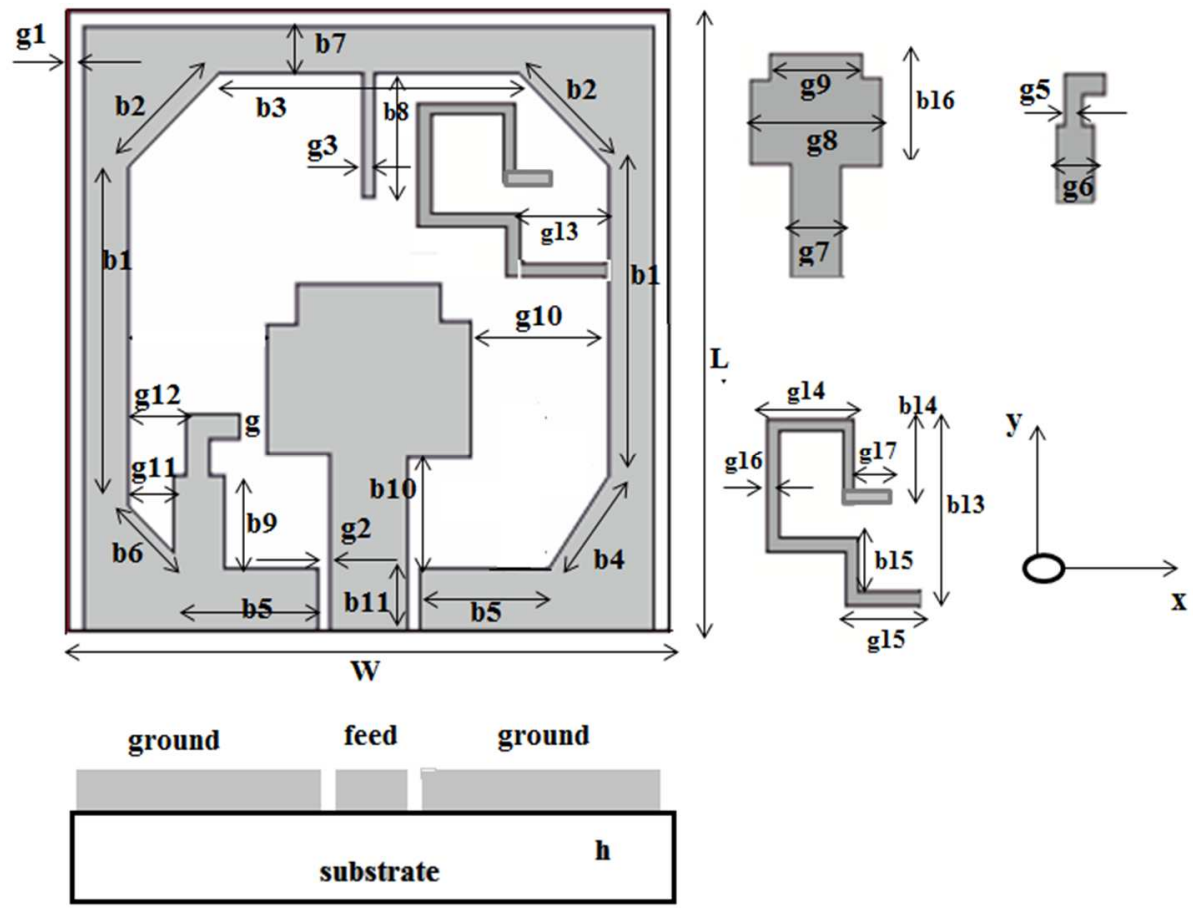

Fig. 1. Proposed Structure of the rectangular patch monopole antenna

Another parameter in the design which has to be optimized to ensure good return loss performance is the vertical separation between the patch and the lower ground plane denoted by 'b10' and its optimal value is found to be equal to $3.5 \mathrm{~mm}$. In the geometry of the proposed antenna, the overall length of the $\mathrm{L}$-shaped stub $\mathrm{l}_{2}$ is set equal to $18.6 \mathrm{~mm}$ to cause a resonance at $2.42 \mathrm{GHz}\left(\mathrm{l}_{2}=0.25 \lambda\right)$. Similarly, the effective monopole height (b10+b16) is $9.2 \mathrm{~mm}$ which approximates $0.29 \lambda$ at 5.88 GHz. The dimensions of all the parameters of the proposed antenna are listed in Table -2 .

Table 2 - Optimal parameters of the proposed antenna

\begin{tabular}{|l|l|l|l|l|l|l|l|l|l|l|l|l|}
\hline Parameter & $\mathrm{L}$ & $\mathrm{W}$ & $\mathrm{b} 1$ & $\mathrm{~b} 2$ & $\mathrm{~b} 3$ & $\mathrm{~b} 4$ & $\mathrm{~b} 5$ & $\mathrm{~b} 6$ & $\mathrm{~b} 7$ & $\mathrm{~b} 8$ & $\mathrm{~b} 9$ & $\mathrm{~b} 10$ \\
\hline Value $(\mathrm{mm})$ & 20 & 20 & 11 & 3.6 & 12 & 2.8 & 4.3 & 2.8 & 1.5 & 4 & 3 & 3.7 \\
\hline Parameter & $\mathrm{b} 11$ & $\mathrm{~b} 12$ & $\mathrm{~b} 13$ & $\mathrm{~b} 14$ & $\mathrm{~b} 15$ & $\mathrm{~b} 16$ & $\mathrm{~g} 1$ & $\mathrm{~g} 2$ & $\mathrm{~g} 3$ & $\mathrm{~g} 4$ & $\mathrm{~g} 5$ & $\mathrm{~g} 6$ \\
\hline Value $(\mathrm{mm})$ & 2 & 5 & 6.6 & 3.3 & 2.4 & 5.5 & 0.5 & 0.5 & 0.4 & 0.5 & 0.8 & 1.7 \\
\hline Parameter & $\mathrm{g} 7$ & $\mathrm{~g} 8$ & $\mathrm{~g} 9$ & $\mathrm{~g} 10$ & $\mathrm{~g} 11$ & $\mathrm{~g} 12$ & $\mathrm{~g} 13$ & $\mathrm{~g} 14$ & $\mathrm{~g} 15$ & $\mathrm{~g} 16$ & $\mathrm{~g} 17$ & $\mathrm{G}$ \\
\hline Value $(\mathrm{mm})$ & 3 & 6.8 & 4.8 & 4.6 & 1.5 & 1.9 & 2.5 & 3.4 & 3 & 0.5 & 1.1 & 0.9 \\
\hline
\end{tabular}

\section{A. Proposed Antenna Evolution}

Fig. 2 shows the evolution stages of the proposed rectangular patch antenna and the corresponding reflection coefficients $\left(S_{11}\right)$ are shown in Fig. 3. In the initial design (Antenna 1 and Antenna 1 (a)), an octagonal shaped slot etched on the ground plane and is excited by a $50 \Omega \mathrm{CPW}$ fed line terminated on a rectangular patch. To enhance the impedance bandwidth and for generating the lower resonance frequency at $2.42 \mathrm{GHz}$, the initial design is modified and the modified versions are named 
Antenna 1(b), Antenna 1(c), Antenna 1(d) and finally, the proposed antenna. It can be seen from Fig. 3, that in Antenna 1, Antenna 1(b), Antenna 1(c), Antenna 1(d) and the proposed antenna, multiple resonances are generated by virtue of adding the rectangular and L-shaped tuning stubs to the ground structure and thus the new lower resonance frequency and good impedance bandwidth are achieved.

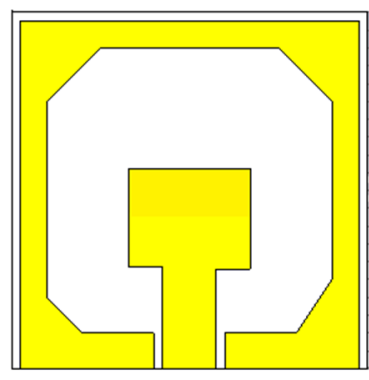

Antenna \# 1

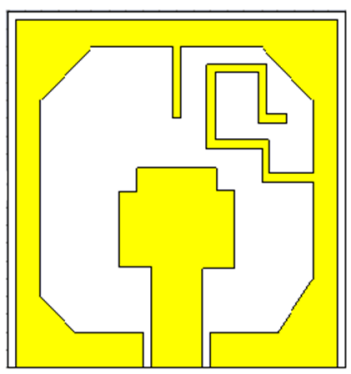

Antenna \#1 (c)

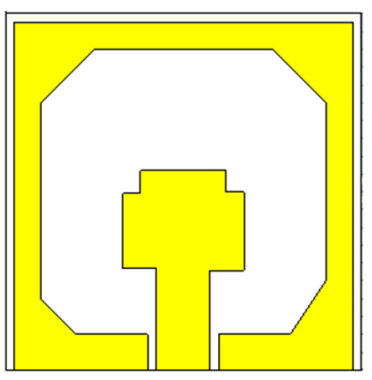

Antenna \#1 (a)

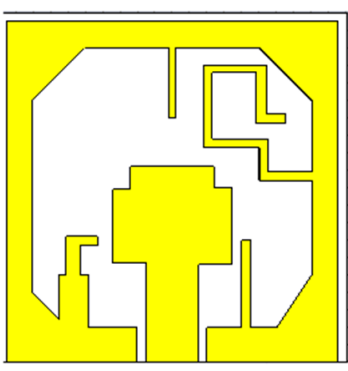

Antenna \# 1 (d)

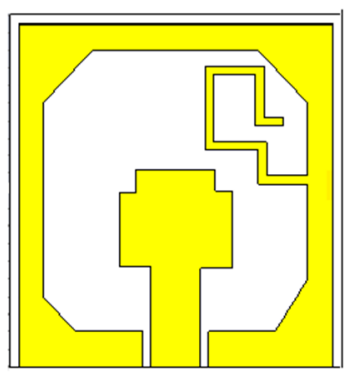

Antenna \#1 (b)

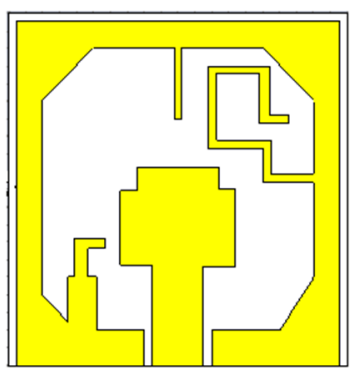

Proposed antenna

Fig. 2. The evaluation process of the proposed rectangular patch antenna

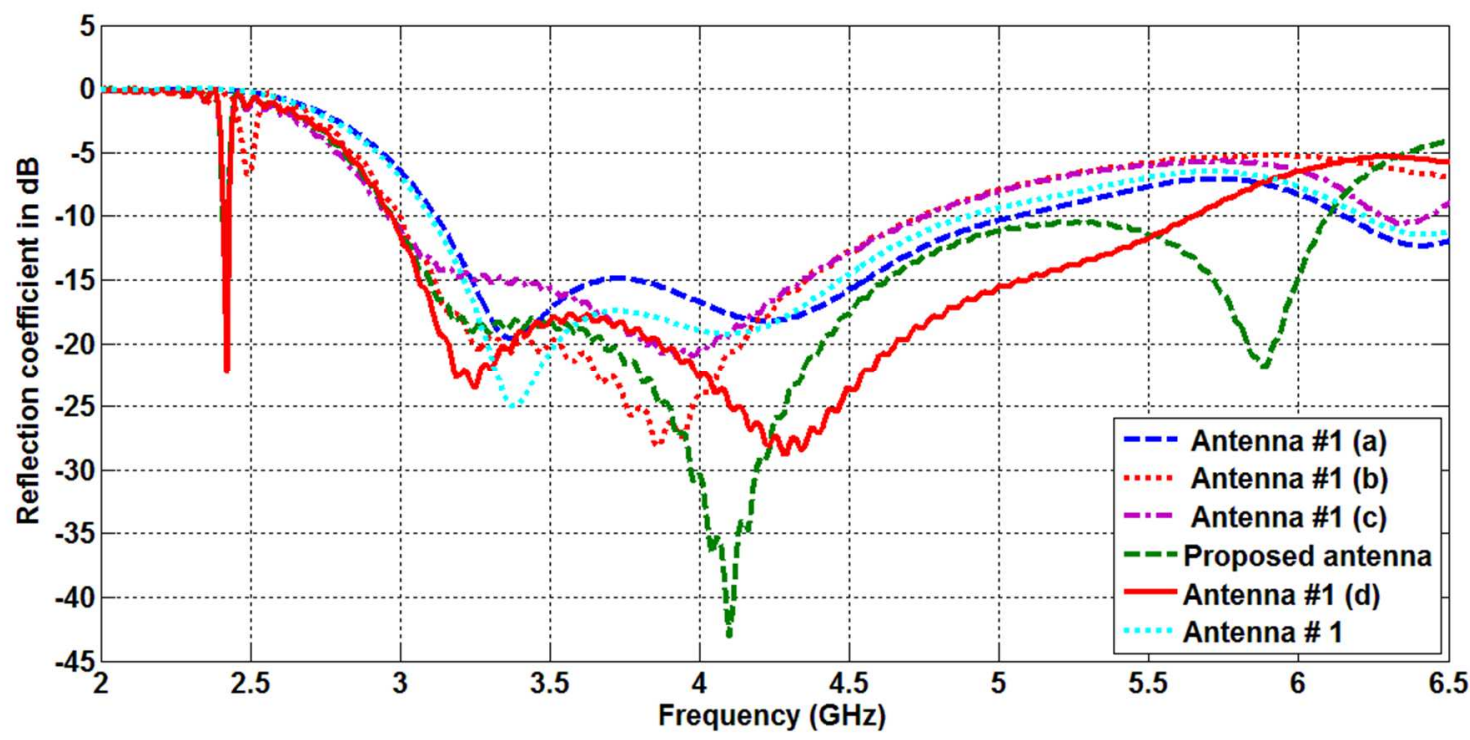

Fig. 3. Simulated $S_{11}$ for prototypes Antenna \#1(a), Antenna \#1(b), Antenna \#1(c),Antenna \#1(d) and proposed antenna

\section{SIMULATED AND EXPERIMENTAL RESULTS}

The proposed antenna is designed using the commercial electromagnetic software CST Microwave Studio and fabricated with optimized dimensions given in Table 1. Fig. 4 shows the fabricated prototype of the proposed rectangular patch antenna along with the measured and simulated (with and without adding L-shaped stub) reflection coefficients. The measurements have been performed using 
Rohde \& Schwarz Vector Network Analyzer (R\&S ZVA-40). The measured impedance bandwidth of the octagonal slotted rectangular patch antenna is from $3.2 \mathrm{GHz}$ to $6.1 \mathrm{GHz}(2.9 \mathrm{GHz})$ with an additional band of $60 \mathrm{MHz}$ from 2.40 to $2.46 \mathrm{GHz}$ which cover the $2.4 \mathrm{GHz}$ WLAN band. In Fig. 4, the curves for measured and simulated reflection coefficients are in good agreement. The slight difference between the measured and simulated results is due to fabrication constraints, uncertainties in the dielectric constant and substrate thickness, soldering effects and the quality of the SMA connector used.
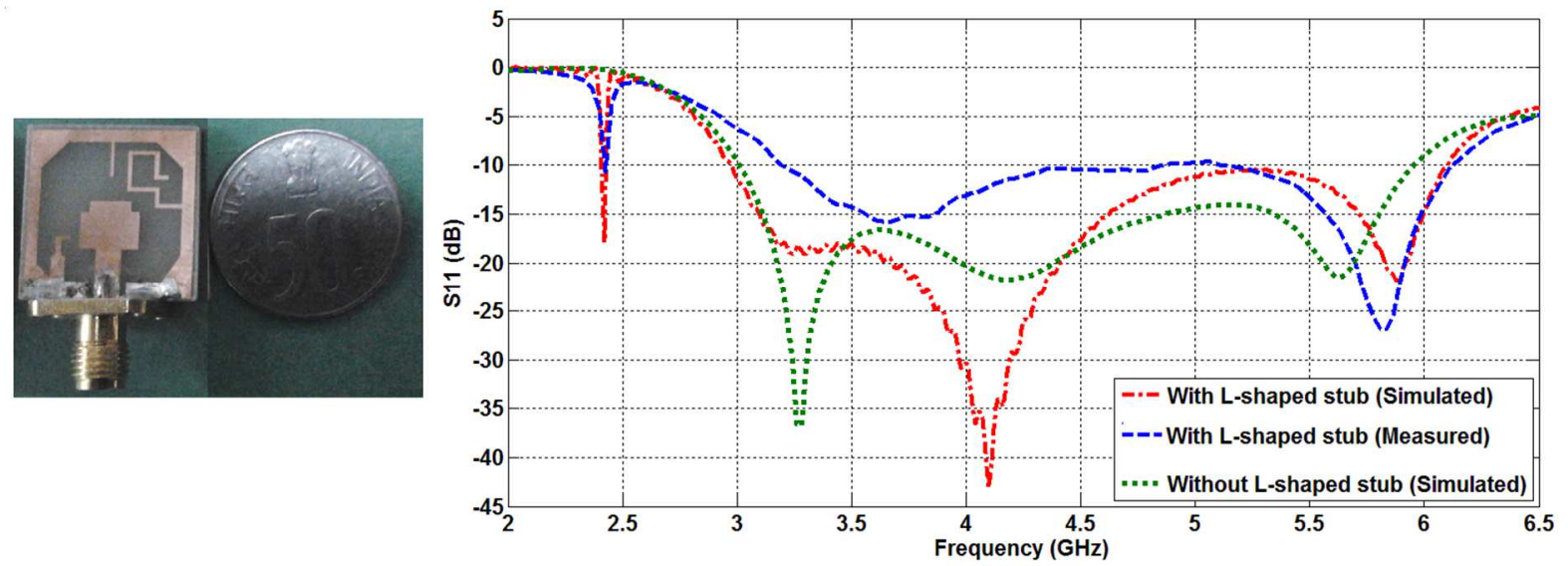

Fig. 4. Photograph of the proposed rectangular patch antenna with its corresponding simulated and measured return loss.

The reflection coefficient characteristics of the proposed antennas can also be explained by observing the current distributions of the proposed antenna. The surface current distributions of the rectangular patch antenna at $2.45 \mathrm{GHz}, 3.5 \mathrm{GHz}, 4.2 \mathrm{GHz}$ and $5.85 \mathrm{GHz}$ is given in Fig. 5. In the figure, the red colour indicates maximum current density while blue colour indicates minimum current density. We can see that at low frequencies, maximum current is distributed on the L-shaped stub and the octagonal slot. Similarily at the high frequencies maximum current is distributed on the patch and very less current on the L-shaped stub and the octagonal slot. Thus, the current distributions justify the conclusions drawn previously wherein the lower resonances were attributed to the L-shaped stub and the slot and the higher resonances were attributed to the patch.
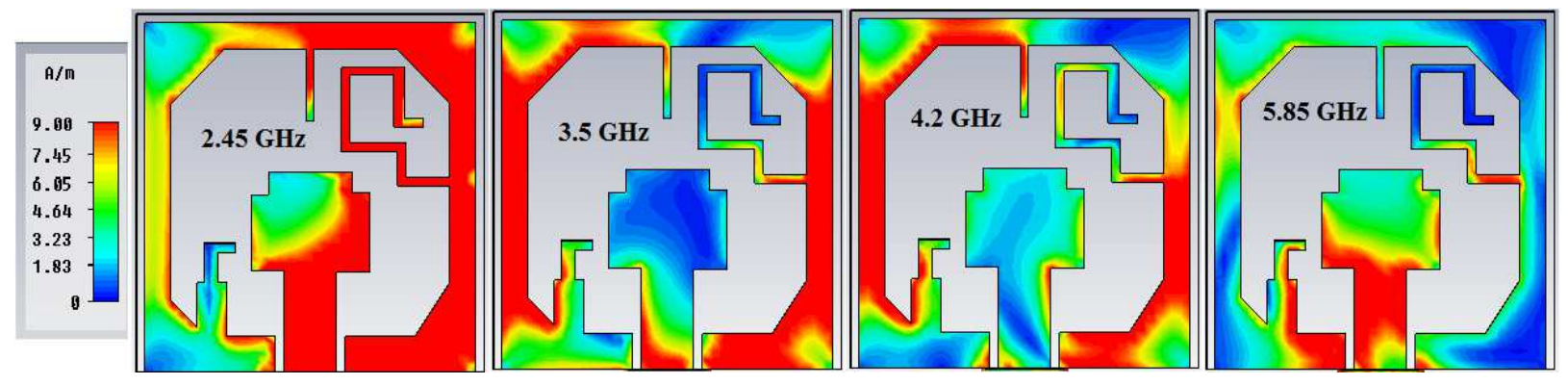

Fig. 5. Surface current (magnitude) distribution at different resonances for the proposed dual-band antenna 


\section{THEORETICAL ANALYSIS}

The contributing factor for the first resonance $\left(f_{R 1}\right)$ in the final version of the rectangular patch antenna near $2.42 \mathrm{GHz}$ is the L-shaped tuning stub of length $\mathrm{l}_{2}=18.6 \mathrm{~mm}$ (Fig. 6) and the resonance frequency is approximately obtained from equation (1). The second resonance near $5.88 \mathrm{GHz}$ is due to the patch height and dependent on the coupling between the lower edge of the patch and the upper edge of the ground plane. The second resonance frequency for the proposed antenna can be obtained from the equation (2).

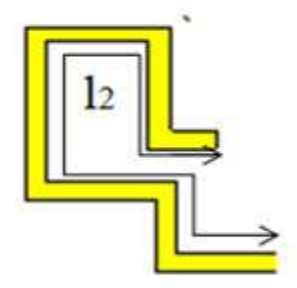

Fig. 6. L-shaped tuning stub of the proposed rectangular patch antenna

$$
\begin{gathered}
f_{R 1}=\frac{C}{4 l_{2} \sqrt{\varepsilon_{r, e f f}}} \\
f_{R 2}=\frac{0.29 C}{l_{4} \sqrt{\varepsilon_{r, e f f}}} \\
\text { Where } \quad l_{4}=b_{10}+b_{16} \\
\varepsilon_{r, \text { eff }}=\frac{\varepsilon_{r}+1}{2}
\end{gathered}
$$

Here, $\mathrm{c}$ stands for the speed of light in free space, $l_{4}$ is the effective monopole height as given in equation (3), while $\varepsilon_{\mathrm{r}, \text { eff }}$ is the effective relative permittivity to be calculated from equation (4). For calculating the effective relative permittivity, it is assumed that for a CPW fed monopole, half of the established field lies in air while the remaining half is distributed in the substrate. The resonance frequencies are calculated using equations (1) to (4).

\section{PARAMETRIC STUDY}

\section{A. Effect of the Separation between Patch and Ground}

The separation between the patch and the ground plays a crucial role in obtaining wider impedance bandwidth. Fig. 7 shows the variation in return loss by varying the separation between the patch and the ground. It can be seen from the figure that a smaller separation gives better impedance matching at higher frequencies. Hence, the separation b10 needs to be optimized and the optimum value is found to be $3.7 \mathrm{~mm}$. At this optimum value, the maximum coupling of electromagnetic energy between the patch and the ground is achieved over a wider bandwidth. 


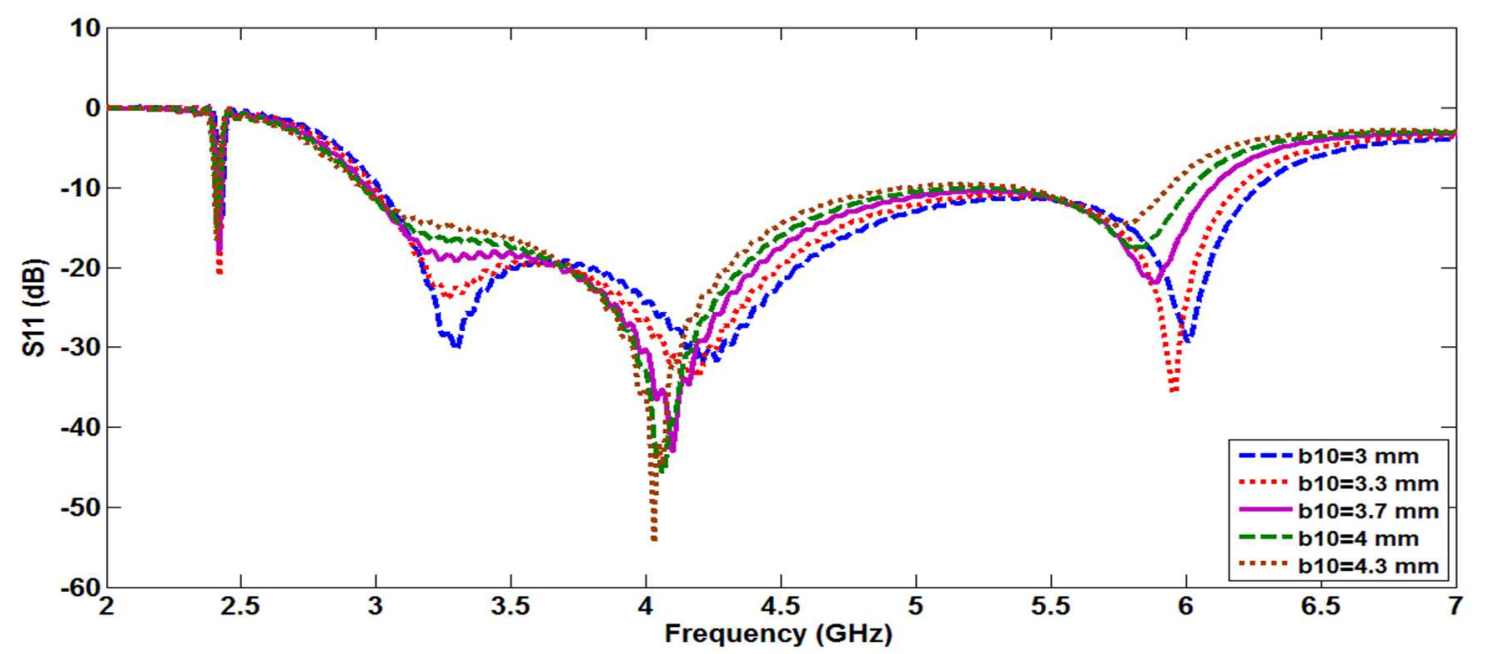

Fig.7. Effect of varying the separation gap on return loss

\section{B. Effect of Varying the L-shaped tuning stub length}

The effect of varying the overall length ' 12 ' of the L-shaped tuning stub on return loss is given in Fig. 8. It can be seen from the figure that as the length ' 12 ' increases, the first resonance and higher cut-off frequency shifts towards the lower frequency side. Hence an optimum value of $18.6 \mathrm{~mm}$ is considered for the proposed antenna in order to get the first resonance frequency at $2.4 \mathrm{GHz}$.

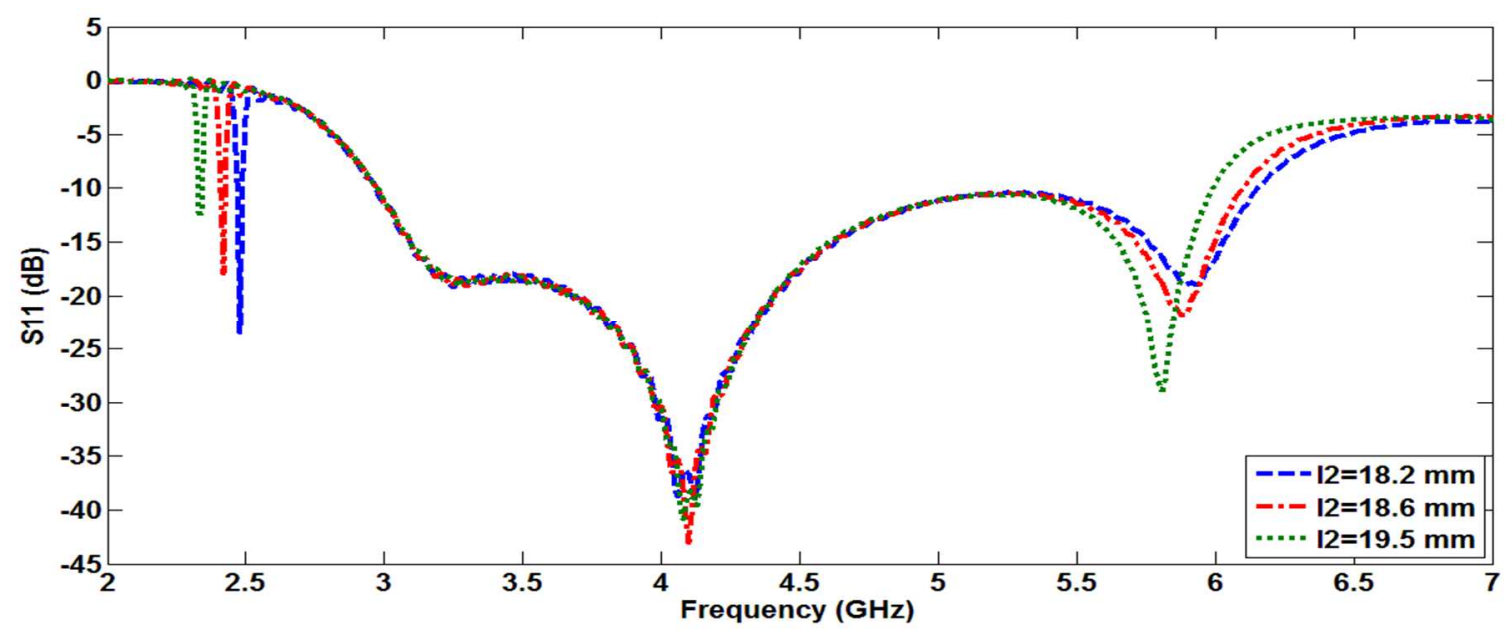

Fig. 8. Effect of varying L-shaped tuning stub length on return loss

\section{Effect of Varying the stub height}

The effect of varying the height 'b8' of the vertical stub on the return loss is given in Fig. 9. It can be seen from the figure that as the height ' $\mathrm{b} 8$ ' increases, the return loss at the first resonance frequency becomes more than $-10 \mathrm{~dB}$ because of improper coupling between the vertical stub (above the patch ) and the L-shaped stub. Hence, an optimum value of $4 \mathrm{~mm}$ is considered for the proposed 
antenna in order to get first resonance frequency at $2.4 \mathrm{GHz}$ band as well as good overall impedance matching.

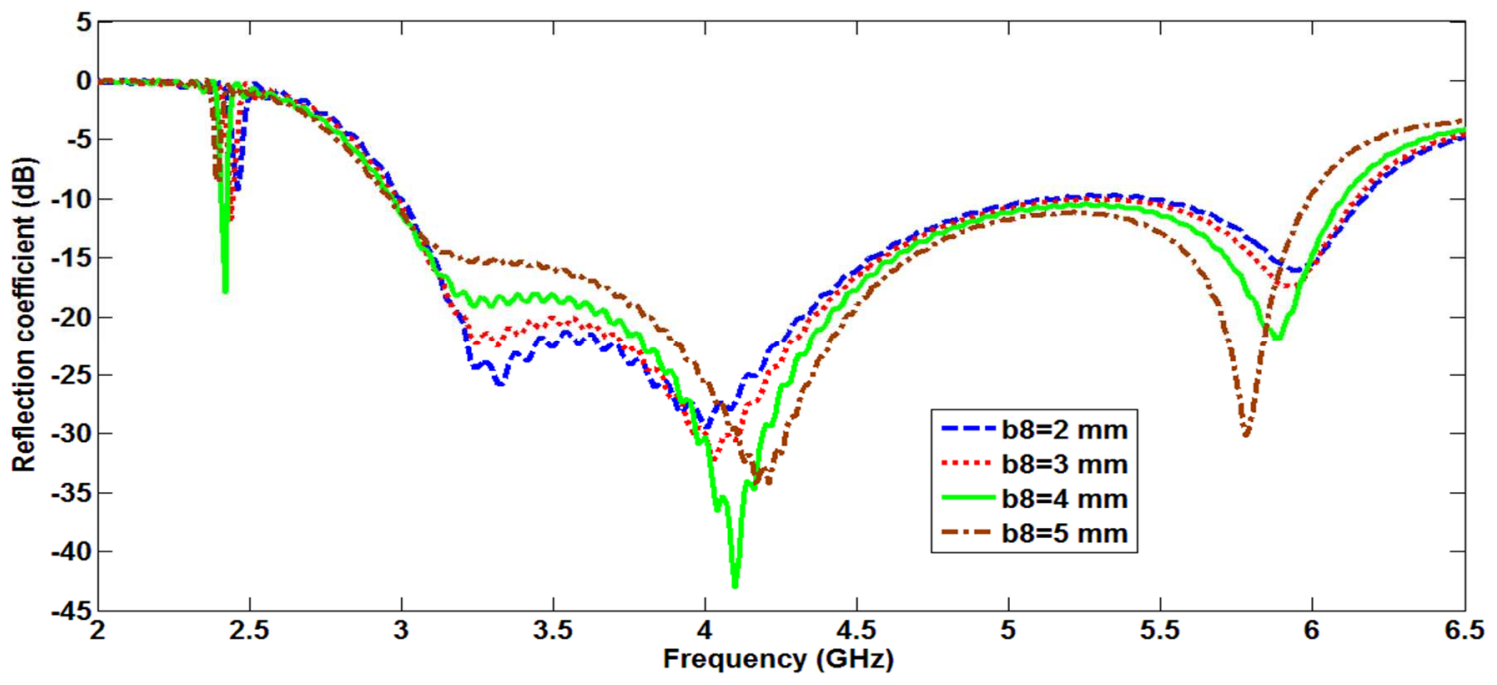

Fig.9. Effect of varying stub height 'b8' on return loss

D. Effect of Varying the patch width ' $g 9$ ' and width ' $w 1$ '

Fig. 10 (a) shows the effect of varying the parameter ' $g 9$ ' on the return loss characteristics. As the patch width ' $\mathrm{g} 9$ ' decreases, the return loss magnitude and impedance bandwidth of second operating band improves. Also it can be seen from the figure that between $4.5 \mathrm{GHz}$ to $5.5 \mathrm{GHz}$ frequency band the return loss magnitude has become $-12 \mathrm{~dB}$ with two-stepped patch. So in the final design a twostepped patch has been considered. As further decreases the ' $\mathrm{g} 9$ ' value then return is deteriorates at some resonance frequencies as well as improving at other frequencies so an optimum value of $4.8 \mathrm{~mm}$ has been considered in the fabricated prototype. Similarly, the effect of parameter step patch length w1 on return loss characteristics and bandwidth is shown in Fog 10 (b). These parameters g9 and w1 of stepped patch add the one more degree of freedom in design.

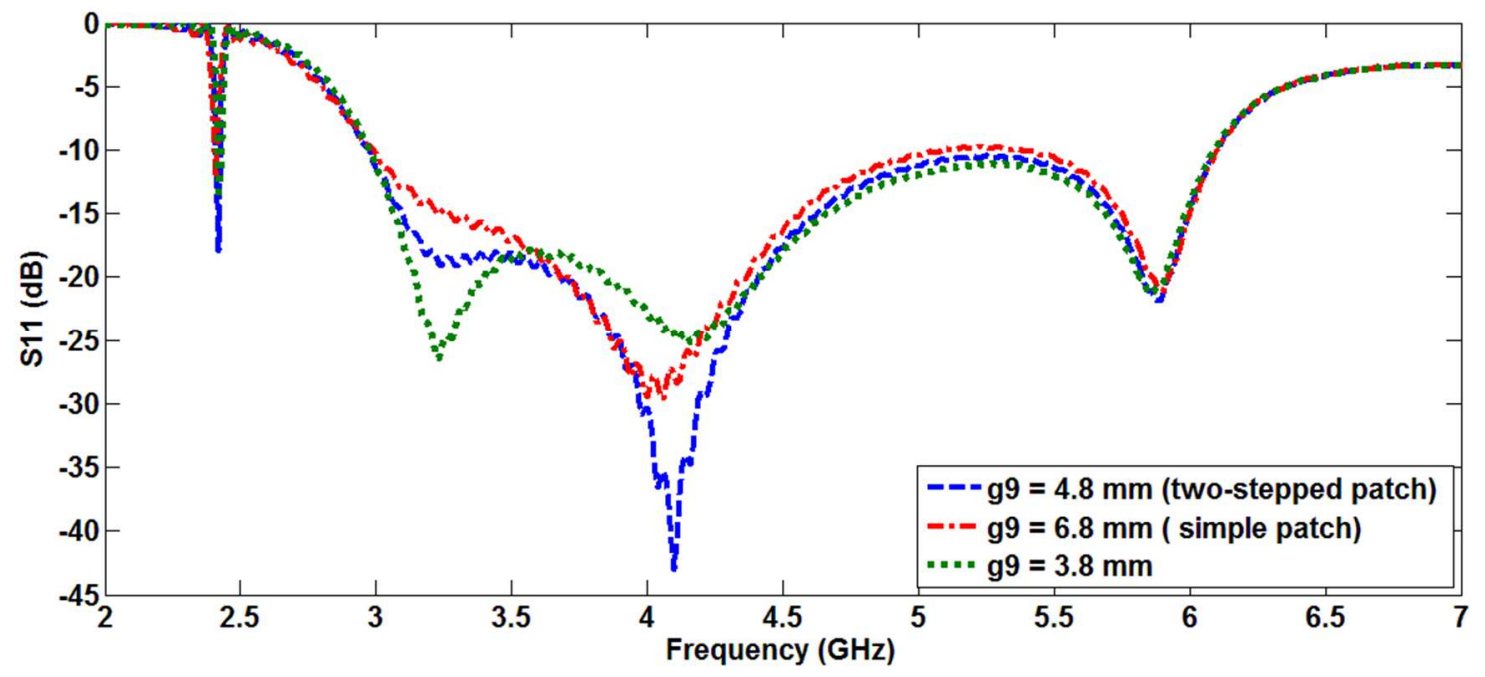

Fig.10 (a). Effect of varying patch width 'g9' on return loss 


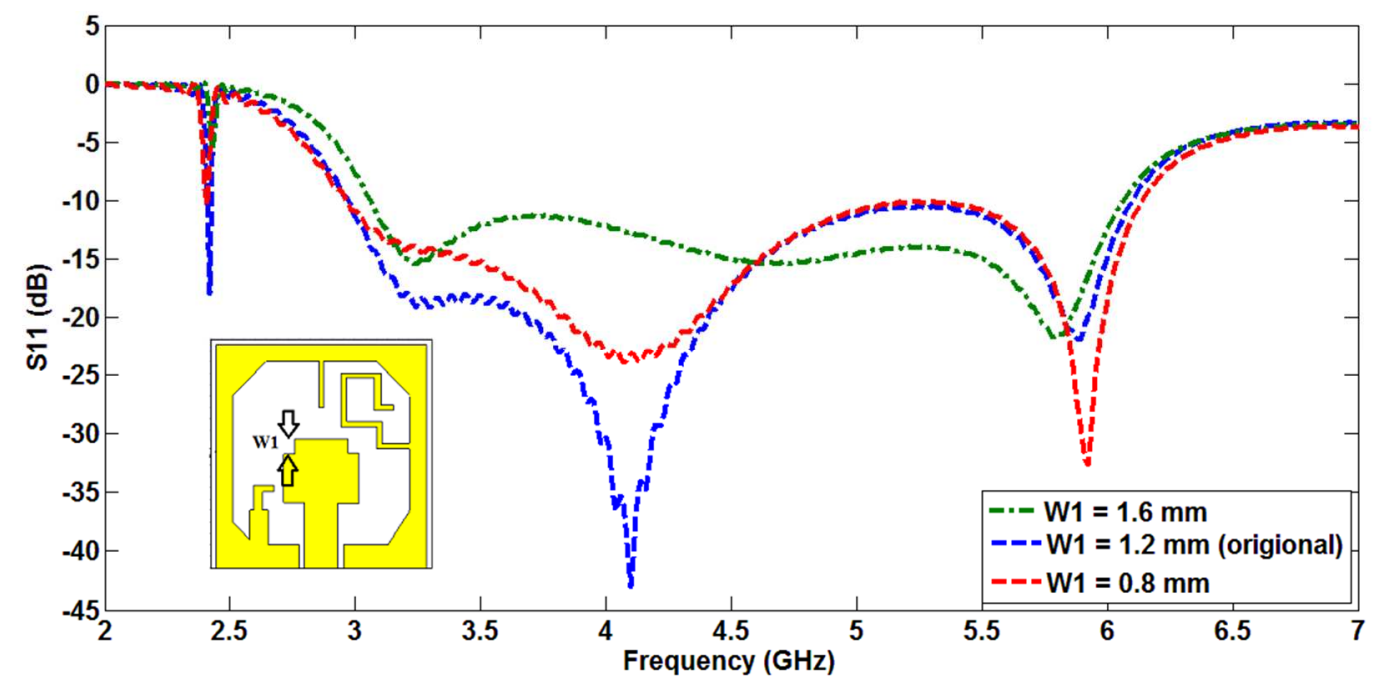

Fig.10 (b). Effect of varying patch length 'w1' on return loss

\section{RADIATION PATTERNS AND GAIN}

The radiation patterns of the octagonal slotted rectangular shaped patch antenna is simulated in the Eplane and H- plane using CST Microwave Studio and measured in an in-house anechoic chamber using antenna measurement system. A standard double ridged horn antenna is used as reference antenna. The simulated and measured radiation patterns of the proposed antenna are shown in Fig. 11 for different frequencies. The H-plane radiation has omni-directional pattern while the E-plane radiation has bidirectional (dumb bell shaped) pattern. For both the cases, the simulated and measured results are found to be in close agreement with a little difference due to measurement and alignment errors. The simulated and measured peak gain across the operating bands for the proposed antenna is illustrated in Fig. 12. As can be seen, stable gain across desired band has been achieved. The peak gain remains between $-1 \mathrm{~dB}$ to $5 \mathrm{~dB}$ in the useful band and increases with frequency due to the increased effective area of the antenna at shorter wavelengths. The radiation efficiency characteristics of the proposed antenna was calculated by using CST Microwave Studio and in the first operating band efficiency is about $73 \%$ while in the second operating band it is about $84 \%$. At smaller frequencies, the antenna becomes smaller when compared to the wavelength. Hence, the antenna becomes more like a transmission line rather than as radiating element. Hence, even when the return loss is better, the part of the energy radiated becomes less. Hence, the gain and efficiency are less at lower frequencies as seen in simulations. The stable radiation patterns with a reasonable gain make the proposed antenna suitable for being used in WLAN/WiMAX and UWB communication applications. 

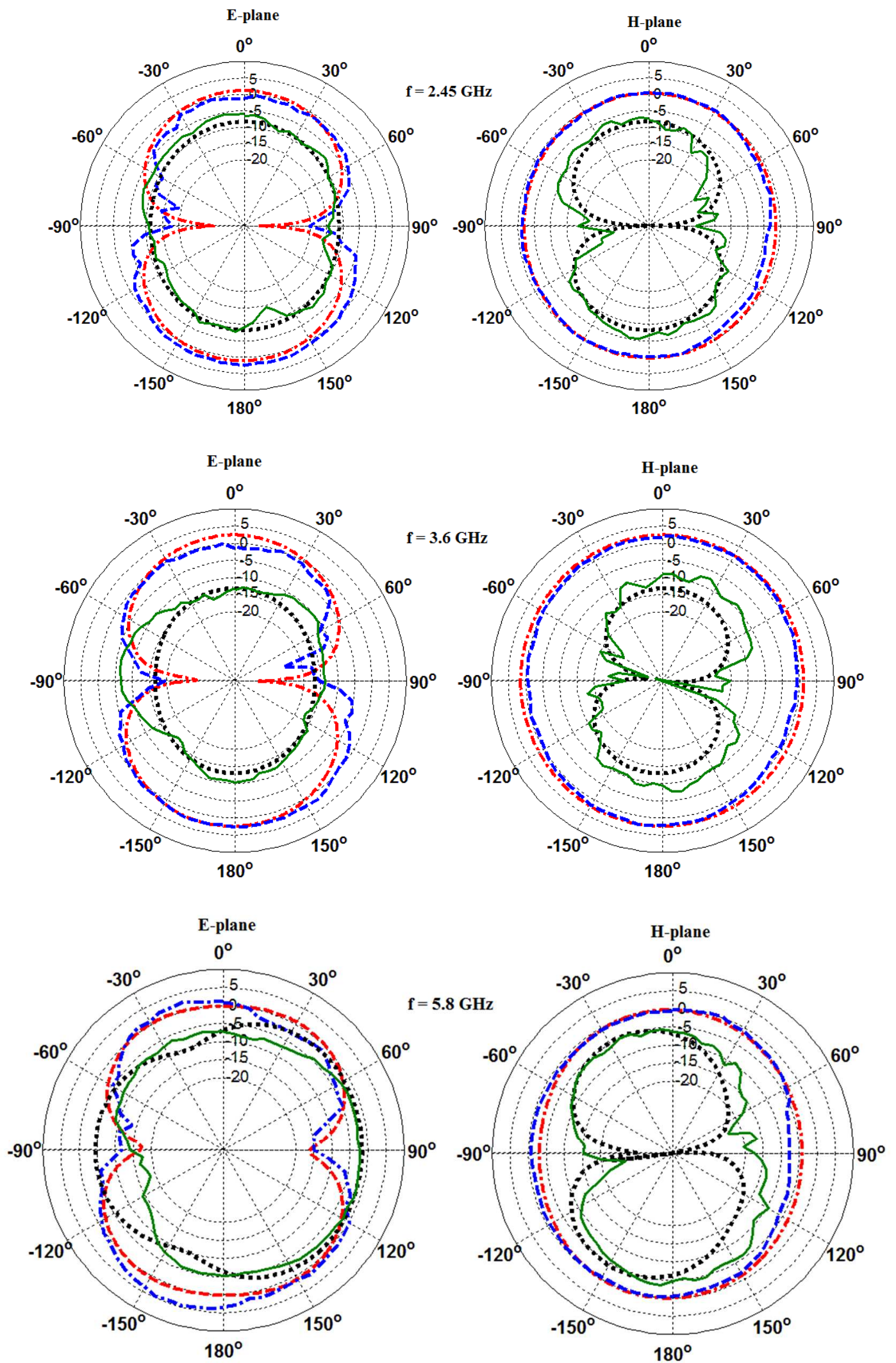

--- co simulated $-\cdot-$ co measured $\ldots$ cross simulated - cross measured

Fig. 11. Measured and simulated radiation patterns of rectangular shaped patch antenna at $2.45 \mathrm{GHz}, 3.6 \mathrm{GHz}$ and $5.8 \mathrm{GHz}$ frequencies 


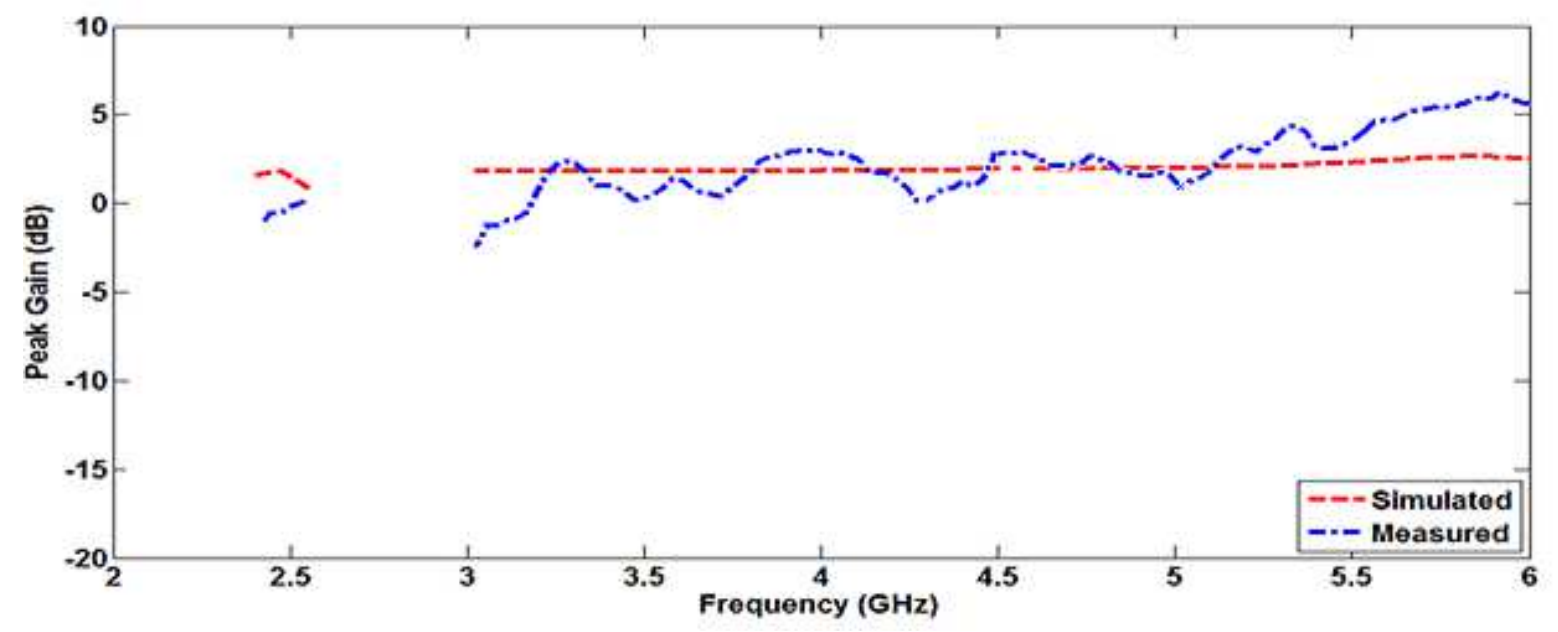

Fig.12. Simulated and measured peak gain of the proposed dual-band antenna

\section{CONCLUSIONS}

A compact octagonal slotted rectangular shaped patch antenna utilizing a $50 \Omega \mathrm{CPW}$-fed structure is proposed. The antenna operates in 2.4/5.2/5.8 GHz WLAN frequency bands, 3.5/5.5 GHz WiMAX bands and 3.2-6.2 GHz DS-CDMA/MB-OFDM UWB band systems. Thin metallic rectangular shaped stubs are used to generate the lower resonance at to cover the $2.4 \mathrm{GHz}$ WLAN band. The effects of various design parameters are studied thoroughly. The simulated results are found to be in good agreement with the experimental results. The radiation patterns of the antenna are omni-directional in H-plane and bidirectional in E-plane. The gain obtained over the operating band is acceptable.

\section{ACKNOWLEDGEMENT}

The first author is a doctoral student at Symbiosis International University, (Deemed University), Pune, India and acknowledges DIAT (Deemed University), Pune for the facilities extended and R.V.S. Rama Krishna and Nagendra Kushwaha for their technical suggestions.

\section{REFERENCES}

[1] L.-C. Tsai, "A triple-band bow-tie-shaped CPW-fed slot antenna for WLAN applications," Progress In Electromagnetics Research C, Vol. 47, 167-171, 2014.

[2] W. Ren, "Compact dual-band slot antenna for 2.4/5 GHz WLAN applications," Progress In Electromagnetics Research B, Vol. 8, 319-327, 2008.

[3] G. Zhao, F.-S. Zhang, Y. Song, Z.-B. Weng, and Y.-C. Jiao, "Compact ring monopole antenna with double meander lines for 2.4/5 GHz dual-band operation," Progress In Electromagnetics Research, Vol. 72, 187-194, 2007.

[4] Hsiao, H.-M., Wu, J.-W., Wang, Y.-D., Lu, J.-H. and Chang, S.-H. "Novel dual-broadband rectangular-slot antenna for 2.4/5-GHz wireless communication." Microw. Opt. Technol. Lett., 46: 197-201, 2005.

[5] Liu, W.-C, "Broadband dual-frequency cross-shaped slot CPW-fed monopole antenna for WLAN operation.". Microw. Opt. Technol. Lett., 46: 353-355, 2005.

[6] Wu, Jeun-Wen. "2.4/5-GHz dual-band triangular slot antenna with compact operation." Microwave and optical technology letters 45: 81-84, 2005. 
[7] J. R. Panda and R. S. Kshetrimayum, "A printed $2.4 \mathrm{GHz} / 5.8 \mathrm{GHz}$ dual-band monopole antenna with a protruding stub in the ground plane for WLAN and RFID applications," Progress In Electromagnetics Research, Vol. 117, 425-434, 2011.

[8] Su, Chih-Ming, et al. "Dual-band slot antenna for 2.4/5.2 GHz WLAN operation."Microwave and Optical Technology Letters 35: 306-308, 2002.

[9] Yen-Liang Kuo; Kin-Lu Wong, "Printed double-T monopole antenna for $2.4 / 5.2 \mathrm{GHz}$ dual-band WLAN operations," Antennas and Propagation, IEEE Transactions on, vol.51, no.9, pp.2187,2192, Sep 2003.

[10] Zhang, T-L., Z-H. Yan, L. Chen, and Y. Song. "A compact dual-band CPW-fed planar monopole antenna for WLAN applications." Journal of Electromagnetic Waves and Applications 22, no. 14-15 : 2097-2104, 2008.

[11] Y. Song, Y.-C. Jiao, G. Zhao, and F.-S. Zhang, "Multiband CPW-fed triangle-shaped monopole antenna for wireless applications," Progress In Electromagnetics Research, Vol. 70, 329-336, 2007.

[12] Park, Jong K., Hee S. An, and Jung N. Lee. "Design of the tree-shaped UWB antenna using fractal concept." Microwave and Optical Technology Letters 50, no. 1: 144-150, 2008.

[13] Song, Hyo W., Jong K. Park, and Jin H. Yoo. "A novel ultra-wideband monopole antenna with two symmetrical strips." Microwave and Optical Technology Letters 50, no. 11: 2845-2848, 2008. 